\title{
PRINCÍPIO DA CONFIDENCIALIDADE E PRINCÍPIO DA PUBLICIDADE: INCIDÊNCIA E LIMITES SOBRE AS TRATATIVAS CONCILIATÓRIAS NAADMINISTRAÇÃO PÚBLICA
}

\author{
Principle of confidentiality and principle of publicity: Incidence \\ and limits about the conciliation in the Public Administration
}

\section{Tatiana de Marsillac Linn Heck}

Advogada da União, Mestre em Direito pelo UNICEUB, Mediadora certificada pelo ICFML, membro da Comissão Especial de Mediação e Práticas Restaurativas da OAB/RS, responsável pela Câmara Local de Conciliação no RS- CLC-RS/CGU/AGU.

\section{Luciana Marques Bombino}

Procuradora do Banco Central, Graduada pela Universidade Federal de Viçosa, conciliadora da Câmara de Conciliação da Administração Federal - CCAF/CGU/AGU.

\begin{abstract}
Resumo
O presente trabalho se propõe a construir um adequado modo de aplicação dos princípios da confidencialidade e da publicidade nos procedimentos de mediação em que é parte a Administração Pública. Trata da cedência recíproca entre os princípios, de modo a resguardar os direitos e interesses dos particulares e permitir o amplo controle e fiscalização da Administração Pública pelos administrados. Para isso, busca na doutrina o entendimento acerca do conteúdo e função do princípio da confidencialidade na mediação, a fim de melhor compreender como deve ser encarado nas mediações que se travam na Administração Pública. Aborda as experiências da mediação no poder público nos Estados Unidos e países europeus, a fim de avaliar o modo como a questão vem sendo tratada ali, e também na doutrina brasileira. Traz o direito público consensual como campo teórico que embasa a o que se entende ser a visão adequada sobre o tema.
\end{abstract}

Palavras-chave: Mediação. Administração Pública. Princípios. Confidencialidade. Publicidade. Direito público consensual.

\begin{abstract}
This paper proposes to construct an adequate way of applying the principles of confidentiality and publicity in the mediation procedures in which the Public Administration is part. It deals with the relation between the principles, so as to safeguard the rights and interests of individuals and allow the broad control and supervision of the Public Administration by the administrators. For this, it seeks in the doctrine the understanding about the content and function of the principle of confidentiality in mediation, in order to better understand how it should be faced in the mediations that are in the Public Administration. It addresses the experiences of mediation in public power in the United States and European countries, in order to evaluate how the issue is being dealt with there, and also in Brazilian doctrine. It brings consensual public law as a theoretical field that supports what is understood to be the proper view on the subject.
\end{abstract}

Keywords: Mediation. Public Administration Principles. Confidentiality. Publicity. Consensual public law 


\section{Sumário}

1. Introdução: novos paradigmas legais; 2. Conceituação das ferramentas da mediação e da conciliação; 2.1 Do princípio da confiança; 2.2. Confiança e confidencialidade; 3. Confidencialidade e mediação na Administração Pública no direito comparado; 3.1 A confidencialidade nas mediações relativas à Administração Pública nos Estados Unidos; 3.2. A confidencialidade nas mediações relativas à Administração Pública no direito europeu; 4. Confidencialidade nos procedimentos conciliatórios entre particulares e a Administração Pública e confidencialidade entre órgãos e entidades da Administração Pública no Brasil; 4.1. Divergências em relação à aplicação da confidencialidade; 5. Direito público consensual; 6. Conclusão; 7. Notas; Referências.

\section{INTRODUÇÃO: NOVOS PARADIGMAS LEGAIS}

A edição da Lei $n^{\circ} 13.140$, de 2015 , ocorreu logo após à promulgação da Lei $n^{\circ}$ 13.105, de 16 de março de 2015, que estabeleceu o Novo Código de Processo Civil. O art. $3^{\circ}, \S 2^{\circ}$ do Novo Código de Processo Civil institui como nova norma fundamental processual o princípio da promoção pelo Estado da solução por autocomposição. Esse artigo consagra um princípio de atuação do Estado: "O Estado promoverá, sempre que possível, a solução consensual dos conflitos". Trata-se, portanto, da instituição de uma nova política pública que prioriza a solução consensual dos conflitos. Se isso, de um lado, importa em tratar as questões que envolvem o Estado com as flexíveis ferramentas da autocomposição, de outro traz o desafio de que esse novo instrumento, até agora menosprezado pelo direito pátrio, seja utilizado no ambiente do direito administrativo, pautado pelos princípios, leis e regulamentos, sem que esse arcabouço jurídico já existente impeça a rediscussão e revisão de certos dogmas estabelecidos no ordenamento.

O novo dispositivo legal consolidou no ordenamento a Resolução 125/2010 do CNJ que já disciplinava a solução consensual.

$\mathrm{Na}$ mesma esteira segue o $\S 3^{\circ}$ do art. $2^{\circ}$ do NCPC ao determinar que o estímulo da solução consensual deve ser disseminado por toda a sociedade e não apenas pelo Poder Público. Todo o Novo Código de Processo Civil é estruturado sobre o estímulo à autocomposição. A posterior promulgação da Lei n 13.140, de 2015 enriqueceu ainda mais o arcabouço jurídico ao tratar mais minudentemente a conciliação de controvérsias entre particulares, entre particulares e Administração Pública e apenas entre órgãos e entidades da Administração Pública.

É importante destacar que a resolução pacífica dos conflitos por meio de ferramentas autocompositivas propicia a emancipação do Poder Público nos processos decisórios de seu interesse, bem como confere ao particular a prerrogativa de construir soluções para a preservação de seus direitos, dispensando-se, nestes casos, a tutela do Poder Judiciário.

Nesse contexto, faz-se necessário tratar da aplicação dos arts. $2^{\circ}$, inc. VII; 30 e 31 da Lei $n^{\circ} 13.140$, de 26 de junho de 2015 aos procedimentos conciliatórios, tendo sob foco o aparente conflito normativo entre os dispositivos mencionados e as disposições constante na Lei $n^{\circ} 12.527$, de 18 de novembro de 2011, a Lei de Acesso à Informação.

\section{CONCEITUAÇÃO DAS FERRAMENTAS DA MEDIAÇÃO E DA CONCILIAÇÃO}

Cabe, neste momento, apenas por didatismo, esclarecer que a doutrina distingue os institutos da mediação e da conciliação, distinção esta que foi acolhida, ao menos concei- 
tualmente, pelo Novo Código de Processo Civil, que nos parágrafos do art. 165, dispõe:

\begin{abstract}
$\S 2^{\circ} \mathrm{O}$ conciliador, que atuará preferencialmente nos casos em que não houver vínculo anterior entre as partes, poderá sugerir soluções para o litígio, sendo vedada a utilização de qualquer tipo de constrangimento ou intimidação para que as partes conciliem.

$\S 3^{\circ} \mathrm{O}$ mediador, que atuará preferencialmente nos casos em que houver vínculo anterior entre as partes, auxiliará aos interessados a compreender as questões e os interesses em conflito, de modo que eles possam, pelo restabelecimento da comunicação, identificar, por si próprios, soluções consensuais que gerem benefícios mútuos.
\end{abstract}

Carlos Eduardo de Vasconcelos conceitua mediação:

Mediação é método dialogal de solução ou transformação de conflitos interpessoais em que os mediandos escolhem ou aceitam terceiros mediador(es), com aptidão para conduzir o processo e facilitar o diálogo, a começar pelas apresentações, explicações e compromissos iniciais, sequenciando com narrativas e escutas alternadas dos mediandos, contextualizações e resumos do(s) mediador(es), com vistas a se construir a compreensão das vivências afetivas e materiais da disputa, migrar das posições antagônicas para a identificação dos interesses e necessidades comuns e para o entendimento sobre as alternativas mais consistentes, de modo que, havendo consenso, seja concretizado o acordo. (VASCONCELOS, 2015, p. 57)

Já a conciliação, ou mediação avaliativa para alguns, pode ser definida como a intervenção proativa de um terceiro imparcial na controvérsia, mediante o exercício do aconseIhamento, da recomendação ou mesmo da apresentação aos interessados de solução que considere justa e adequada à solução da controvérsia.

De todo modo, é importante ressaltar que tal distinção conceitual não foi albergada pela Lei $n^{\circ} 13.140$, de 2015 , que, inclusive, utiliza a expressão mediação em sua acepção coloquial, para denominar o que doutrinariamente se conceitua como conciliação.

\title{
2.1 DO PRINCÍPIO DA CONFIANÇA
}

Embora o art. $2^{\circ}$ da Lei $n^{\circ} 13.140$, de 2015 não tenha elencado dentre seus incisos o princípio da confiança, não há dúvidas de que a natureza da atividade conciliatória tem na confiança um dos seus pilares.

Ademais, embora não elencada topograficamente dentre os princípios que regem a mediação, a confiança foi tratada pela Lei $n^{0} 13.140$, de 2015, em seu art. $9^{\circ}$ :

\footnotetext{
Art. $9^{\circ}$ Poderá funcionar como mediador extrajudicial qualquer pessoa que tenha a confiança das partes e seja capacitada para fazer mediação, independentemente de integrar qualquer tipo de conselho, entidade de classe ou associação, ou nele inscrever-se.
}

O procedimento conciliatório tem por escopo a composição amigável da controvérsia entre os interessados, mediante a intermediação construtiva de um terceiro imparcial. A relação entre conciliador/mediador e interessados é construída sobre os pilares da boa-fé e da confiança. O conciliador/mediador deve ser credor da sinceridade afetiva dos interessados, que somente serão exitosos em suas aspirações de solução autocompositiva da controvérsia se puderem confiar plenamente no conciliador/mediador. O estabelecimento de 
uma relação de confiança entre conciliador/mediador e os interessados é de fundamental importância para o sucesso das tratativas.

A priorização da relação de confiança que deve existir entre o conciliador/mediador é que fundamenta a determinação de um dever de confidencialidade do conciliador/mediador, que ficará impedido de assessorar, representar ou patrocinar qualquer dos interessados, bem como de atuar como árbitro ou testemunha em processos em que tenha atuado como conciliador/mediador.

O princípio da confiança também foi o norteador dos enunciador 43 e 46 da I Jornada de Prevenção e Solução Extrajudicial de Litígios do Conselho da Justiça Federal:

\begin{abstract}
46. Os mediadores e conciliadores devem respeitar os padrões éticos de confidencialidade na mediação e conciliação, não levando aos magistrados dos seus respectivos feitos o conteúdo das sessões, com exceção dos termos de acordo, adesão, desistência e solicitação de encaminhamentos, para fins de ofícios.
\end{abstract}

Em síntese, é preciso que os interessados se sintam seguros e possam compartilhar seus interesses, estratégias e receios com um interlocutor que thes pareça honesto, leal e sincero. Uma política adequada de conciliação/mediação somente será idônea à obtenção de resultados positivos se os usuários desse serviço tiverem a certeza de que poderão se expressar livremente nas reuniões realizadas, sem que se sujeitem ao risco de prejuízos em eventuais demandas futuras, caso a composição amigável não se concretize.

\title{
2.2. CONFIANÇA E CONFIDENCIALIDADE
}

Confiança e confidencialidade são conceitos distintos, embora interdependentes no procedimento conciliatório. Conforme esclarecido no tópico anterior, confiança é o atributo que adjetiva a relação de respeito mútuo calcado na probidade moral de todos os atores interessados na solução de uma determinada controvérsia - conciliador/mediador e representantes das pessoas que contendem.

Já a confidencialidade é a qualidade de discrição e sigilosidade que incide sobre as informações, documentos e propostas expostos no procedimento conciliatório. Enquanto a confiança tem sob foco a relação entre os participantes, a confidencialidade tem por foco o material produzido no curso do procedimento.

Assim, para além da análise da relação de confiança que deve orientar as tratativas conciliatórias, também é importante registrar a confidencialidade como princípio norteador da atividade conciliatória. Tal princípio foi contemplado tanto pelo Novo Código de Processo Civil, em seu art. 166, quanto pela Lei $n^{\circ} 13.140$, de 2015, que tratou mais detidamente a questão.

Trata-se de princípio que rege tanto o procedimento de mediação quanto a atuação dos participantes e do mediador. No que tange ao procedimento, significa dizer que ele é, em regra, sigiloso, diferentemente do que se passa, em regra, com o processo judicial, cuja natureza é pública. As sessões de mediação são privadas e confidenciais, de modo que a presença de outras pessoas requer a expressa autorização dos envolvidos, e não são permitidas gravações ou registros escritos dos atos e dos diálogos, salvo para fins estatísticos (GOLDBERG, et alii, 2006, p. 428). 
Já quanto à incidência do princípio da confidencialidade na atuação do conciliador/ mediador, a Lei $n^{0} 13.140$, de 2015, que estabeleceu novas diretrizes para o incentivo e a condução da mediação e da conciliação como alternativas autocompositivas para a solução de controvérsias, dispôs que, in verbis:

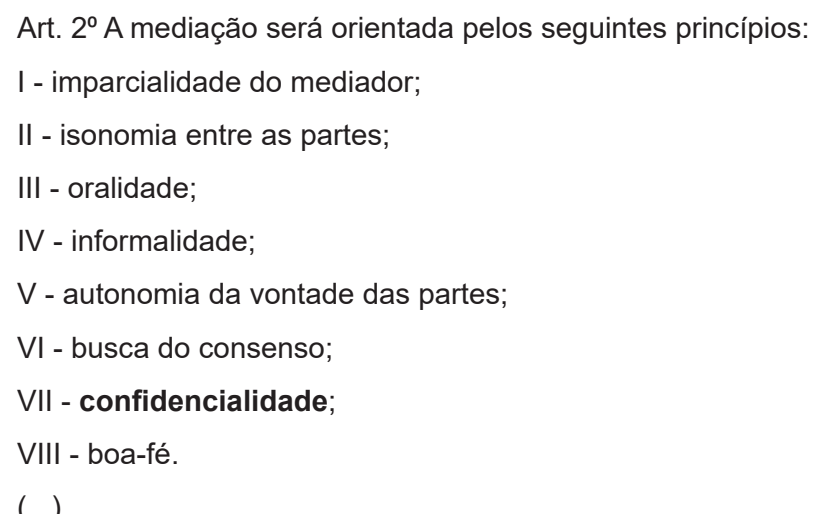

Art. 30. Toda e qualquer informação relativa ao procedimento de mediação será confidencial em relação a terceiros, não podendo ser revelada sequer em processo arbitral ou judicial salvo se as partes expressamente decidirem de forma diversa ou quando sua divulgação for exigida por lei ou necessária para cumprimento de acordo obtido pela mediação.

$\S 10 \mathrm{O}$ dever de confidencialidade aplica-se ao mediador, às partes, a seus prepostos, advogados, assessores técnicos e a outras pessoas de sua confiança que tenham, direta ou indiretamente, participado do procedimento de mediação, alcançando:

I - declaração, opinião, sugestão, promessa ou proposta formulada por uma parte à outra na busca de entendimento para o conflito;

II - reconhecimento de fato por qualquer das partes no curso do procedimento de mediação;

II - manifestação de aceitação de proposta de acordo apresentada pelo mediador;

IV - documento preparado unicamente para os fins do procedimento de mediação.

§ 2o A prova apresentada em desacordo com o disposto neste artigo não será admitida em processo arbitral ou judicial.

§ 3o Não está abrigada pela regra de confidencialidade a informação relativa à ocorrência de crime de ação pública.

$\S 40$ A regra da confidencialidade não afasta o dever de as pessoas discriminadas no caput prestarem informações à administração tributária após o termo final da mediação, aplicando-se aos seus servidores a obrigação de manterem sigilo das informações compartilhadas nos termos do art. 198 da Lei no 5.172, de 25 de outubro de 1966 - Código Tributário Nacional.

Art. 31. Será confidencial a informação prestada por uma parte em sessão privada, não podendo o mediador revelá-la às demais, exceto se expressamente autorizado.

Dos dispositivos colacionados infere-se que as informações recebidas no exercício da atividade de conciliação/mediação são de conteúdo restrito. Tal confidencialidade é tão relevante que o conciliador/mediador pode, inclusive, se escusar de depor como testemunha sobre as atividades presenciadas (art. 166, $\S 2^{\circ}$ do NCPC). Em regra, toda e qualquer informação sobre o procedimento de mediação será confidencial em relação a terceiros, não podendo ser revelada sequer em processo arbitral ou judicial. A confidencialidade estende-se a todas as informações produzidas no curso do procedimento, cujo teor não poderá ser utilizado para fim diverso daquele previsto por expressa deliberação das partes (art. 166, § 
$1^{\circ}$ do NCPC).

A interdependência entre os conceitos pode ser aferida na assertiva de que a confidencialidade das informações dentro do processo de mediação é mais um elemento que influencia na construção de uma relação de confiança entre interessados e entre estes e o conciliador/mediador. Quando os interessados confiam que nada do que foi partilhado no procedimento de conciliação poderá ser levado a público ou utilizado em outro processo em seu desfavor, sentem-se confortáveis para revelar informações relevantes sobre a controvérsia.

Por oportuno, vale observar a respeito o conteúdo de trecho extraído do Manual de Mediação Judicial do Conselho Nacional de Justiça, que, em sua pág. 246, corrobora a relação de interdependência entre os princípios da confiança e da confidencialidade:

\begin{abstract}
Pelo princípio da confidencialidade se estabelece que as informações constantes nas comunicações realizadas na autocomposição não poderão ser ventiladas fora desse processo nem poderão ser apresentadas como provas no eventual julgamento do caso, nem em outros processos judiciais. Nesse sentido, o mediador não pode servir de testemunha acerca de fato relacionado com o seu ofício como facilitador de comunicações. Em regra, pode-se afirmar que a eficiência do mediador está relacionada à confiança que as partes depositam nele e à segurança de que alguns pontos debatidos em mediação não poderão ser utilizados como prova em um processo judicial. Sem poder coercitivo sobre as partes, o mediador depende da melhora da comunicação (se não de uma verdadeira construção de confiança) entre os disputantes. Portanto, a disposição de se expressar com franqueza é essencial à eficácia do processo, isso porque para que as partes possam se comunicar com maior liberdade há de ser garantido o sigilo profissional, para evitar o uso dessas informações em ulterior julgamento.
\end{abstract}

A doutrina reconhece a necessidade de que a mediação se dê em ambiente onde deve ser construída a confiança. Segundo Carlos Eduardo de Vasconcelos (2015, p. 214), os princípios da mediação consubstanciam os seus fundamentos éticos e funcionais. Sua importância deve-se a que a mediação é um conjunto dos valores, técnicas e habilidades, que supõe princípios voltados ao "asseguramento da efetiva facilitação do diálogo, em condições de igualdade de oportunidades e liberdade igual, com vistas à compreensão e ao alcance dessa justiça do caso concreto." (VASCONCELOS, 2015, p. 215).

O princípio da confidencialidade é descrito como aquele que assegura que as necessidades, sentimentos e questões revelados durante a mediação não podem ser utilizados em qualquer outro ambiente (VASCONCELOS, 2015, p. 215).

Também denominado de princípio do sigilo, a exigência de confidencialidade é considerada por muitos autores como essencial para a garantia de que as sessões de mediação ou conciliação possam ter maior chance de sucesso. De acordo com Fernanda Tartuce (2015, p. 209), para que os participantes da sessão consensual possam se expressar com abertura e transparência, é essencial que se sintam protegidos em suas manifestações e contem com a garantia de que o que disserem não será usado contra si em outras oportunidades.

Como bem refere Ravi Peixoto (2015), a relevância do princípio da confidencialidade é tão grande, que, na Diretiva da Mediação editada em 2008 pela União Europeia, embora constem apenas algumas regras gerais, há menção expressa a ele em seu art. $7^{01}$. 
Antônio Carlos Ozório Nunes (2016, p. 223) destaca a confidencialidade como um dos elementos necessários para o estabelecimento do rapport, vínculo que se cria entre o mediador e as partes. O autor considera que a confidencialidade é um dos elementos centrais da mediação, ao lado do clima, do estabelecimento de conexões empáticas, da visualização das coisas do ponto de vista do outro, da percepção da situação de modo imparcial e completo e da descoberta do interesse comum a ser buscado (NUNES, 2016, p. 223).

Sob este prisma, Ozório Nunes afirma a confidencialidade como elemento central da mediação, uma vez que ela embasa a relação de confiança que necessariamente deve existir entre mediador e partes (NUNES, 2016, p. 223). Segundo o autor, "Sem um alto grau de confiança da parte no mediador, a mediação não avança, e o sigilo é aspecto central no estabelecimento desta relação de confiança" (NUNES, 2016, p. 225).

\section{CONFIDENCIALIDADE E MEDIAÇÃO NA ADMINISTRAÇÃO PÚBLICA NO DIREITO COMPARADO}

Em países que tem obtido sucesso na utilização do instituto da mediação, vê-se que o princípio da confidencialidade tende a ser observado, ainda que uma das partes seja a Administração pública. É essa a posição adotada tanto nos Estados Unidos, como em países da Europa, onde a mediação vem se desenvolvendo mais aceleradamente nos anos mais recentes.

\subsection{A CONFIDENCIALIDADE NAS MEDIAÇÕES RELATIVAS À ADMINISTRAÇÃO PÚBLICA NOS ESTADOS UNIDOS}

Nos EUA, a resolução alternativa de $\operatorname{conflitos}^{2}$ no âmbito da Administração Pública ocorre de acordo com as normas dispostas na Administrative Resolution Act, de 1996. Segundo Luciane Moessa de Souza, que fez estudo a respeito do tema no direito estadunidense, em seu teor, a lei federal estendeu a confidencialidade a todas as comunicações entre o mediador ou árbitro e uma das partes. A justificativa para essa medida teria sido a alegação de gestores de órgãos públicos de que a ausência de confidencialidade nas comunicações com os mediadores inibiria o uso da mediação por órgãos públicos. Com base na lei de 1996, foi definido, no âmbito federal, nos EUA, que a publicidade somente abrange o acordo pelo qual se estipula a mediação e o acordo dela resultante, sendo confidenciais todas as demais "comunicações" (termo que abrangeria também documentos técnicos produzidos durante a mediação), exceto quando houver disposição normativa em contrário ou ordem judicial para revelar o conteúdo da comunicação, ordem que somente pode ser proferida para evitar uma grave injustiça, para provar uma violação de regra jurídica ou para evitar dano à saúde ou segurança pública, de magnitude suficientes que supere os danos que serão causados à integridade do processo de resolução de disputas, ao reduzir a confiança das partes em casos futuros de que suas comunicações permanecerão confidenciais (SOUZA, 2014, p. 87-88).

Antes mesmo da legislação clara a respeito, doutrina e jurisprudência dos EUA delinearam critérios acerca da quebra da confidencialidade em conflitos de dimensão pública. Em relação a um dos primeiros casos que envolviam questões ambientais (Richards of Rockford, Inc. v Pacific Gas \& Eletric Co.), em 1976, foi decidido, com base em proposta 
doutrinária, realizar um teste de ponderação, com base em quatro critérios: a) analisar a natureza do processo judicial em que se pretende ver utilizada a informação protegida pela confidencialidade, a fim de verificar se são interesses públicos ou privados que estão em jogo; b) verificar se o depoente era ou não parte no procedimento de mediação em que se pretendia ver quebrada a confidencialidade, a fim de verificar se o depoente estaria revelando interesses próprios ou de terceiros que nele confiaram; c) verificar se a informação que se pretende obter mediante quebra da confidencialidade poderia ser obtida de outra forma ou se aquele depoimento era a única fonte disponível para obtê-la e d) verificar se a informação era absolutamente necessária para resolver o conflito em que se pretende utilizá-la. De acordo com Liepmann (1986-1984, apud SOUZA, 2014, p. 88), no caso em tela, a decisão com base na utilização dos critérios descritos, a corte decidiu que não era o caso de quebra de confidencialidade. Três anos depois, idêntica ponderação foi utilizada no caso Adler v Adams, no Estado de Washington, o que levou ao mesmo resultado (SOUZA, 2014, p. 88).

Autores norte-americanos como Leman defendem que a definição da confidencialidade deva se dar com base em garantias procedimentais, ao invés de ser pautada com base em fatores imponderáveis no momento da mediação, e se aponta um teste proposto por Wigmore, (1972), também baseado em quatro critérios que, se presentes, garantiriam a confidencialidade. São eles:

\footnotetext{
1. as comunicações devem ter sido realizadas na confiança de que permaneceriam confidenciais; 2 . a manutenção da confidencialidade deve ser essencial para uma relação satisfatória de confiança; 3 . deve haver um interesse coletivo na preservação dessa relação; 4. o dano que decorreria da revelação da informação deve ser maior que o benefício oriundo da manutenção da confidencialidade que caracteriza a mediação. (SOUZA, 2014, p. 88).
}

Assim, no direito americano, fica claro que a confidencialidade é princípio que tem sua incidência assegurada, ainda que a mediação envolva entes públicos, sendo a regra, e a publicidade, exceção, que deve ser justificada.

\subsection{A CONFIDENCIALIDADE NAS MEDIAÇÕES RELATIVAS À ADMINISTRAÇÃO PÚBLICA NO DIREITO EUROPEU}

Em estudo que comparou a mediação como procedimento administrativo nas experiências francesa, alemã e inglesa, Alfonso Masucci (2009, p. 33) aponta as principais características do procedimento em cada um destes países, entre as quais destaca a confidencialidade. Segundo contextualiza o autor, na Inglaterra, a mediação ocorre por meio de comum acordo entre as partes e o mediador, acerca de como estruturar o procedimento e, todos os acordos que estabelecem um procedimento de mediação na Administração Pública contém a clausula "without prejudice", que garante a não admissibilidade nem o emprego das informações obtidas durante o procedimento de mediação em sede jurisdicional (MASUCCI, 20019, p. 26). Além dessa, estreitamente ligada à mencionada cláusula, há a "cláusula de segredo", a qual impõe completa reserva sobre as informações que o mediador e as partes possam adquirir durante o desenvolvimento do procedimento, cláusula que se traduz não somente na proibição de divulgar o conteúdo das comunicações estabelecidas entre as partes, e entre estas e o mediador, mas também contém a proibição de utilizar ditas comunicações judicialmente caso o procedimento de mediação não leve a um acordo (MASUCCI, 
2009, p. 26). Como esclarece o autor

una cláusula de este tipo busca en realidad impulsar a las partes a negociar abiertamente, a realizar concesiones. Facilita la comunicación entre las partes y favorece la elaboración de una solución compartida". E acrescenta que a violação à obrigação de reserva sujeita o infrator a uma ação por ressarcimento de danos. (MASUCCI, 2009, p. 26).

Já na França e na Alemanha os sistemas de mediação em matéria administrativa estão mais atrelados à estrutura da Administração pública, o que não impede que também nestes dois países, a mediação de conflitos em direito administrativo preveja o dever de segredo do mediador, o que, ao lado da imparcialidade do mediador, do respeito do princípio do contraditório e do princípio de paridade de armas, asseguram que os procedimentos de mediação administrativa nestes países estejam conformes à filosofia própria aos meios adequados de resolução de conflitos, que buscam conjugar la informalidad del procedimiento, protagonismo del papel de las partes en la definición de la solución del litígio y garantías procedimentales (MASUCCI, 2009, p. 33-34).

Assim, a visão que prepondera é a da confidencialidade como garantia procedimental inerente ao procedimento de mediação tanto nos Estados Unidos, onde conta com mais tempo de tradição, como em diferentes países da Europa, onde a mediação na Administração Pública é tratada com seriedade, na busca de propiciar o sucesso na resolução consensual dos conflitos que envolvem o Estado.

\section{CONFIDENCIALIDADE NOS PROCEDIMENTOS CONCILIATÓRIOS ENTRE PARTICULARES E A ADMINISTRAÇÃO PÚBLICA E CONFIDENCIALIDADE ENTRE ÓRGÃOS E ENTIDADES DA ADMINISTRAÇÃO PÚBLICA NO BRASIL}

A Lei n 13.140, de 2015, disciplinou a mediação entre particulares; a mediação entre particulares e a Administração Pública; e a mediação restrita apenas aos órgãos e entidades da Administração Pública. Interessa-nos especialmente as segunda e terceira hipóteses e sobre elas discorreremos na sequência.

Os arts. $2^{\circ}, 30$ e 31 da Lei no 13.140, de 2015, em síntese, atribuem caráter confidencial às tratativas conciliatórias. Tais disposições são albergadas pelo princípio da inviolabilidade da intimidade e da vida privada, amparado pelo art. $5^{\circ}, \mathrm{X}$, da Constituição Federal de 1988.

O vocábulo 'confidencial', em uma primeira acepção, significa "não divulgável, sigiloso, secreto", já o vocábulo sigilo significa "aquilo que permanece escondido da vista ou do conhecimento" (HOUAISS 2001. p. 796 e 2568). Os arts. $2^{\circ}, 30$ e 31 da Lei $n^{\circ} 13.140$, de 2015 são regras gerais que incidem, em princípio, em todos os procedimentos conciliatórios, não havendo no texto legal qualquer exceção expressa quanto à sua aplicação às tratativas conciliatórias que envolverem a Administração Pública.

De outro lado, embora a Lei n 13.140, de 2015 não abra exceções expressas à confidencialidade, não se pode ignorar o princípio constitucional da publicidade, espraiado por 
todo o texto constitucional, notadamente nos arts. $5^{\circ}$, inc. XXXIII; 37, § $3^{\circ}$, inc. II e 216, $\S 2^{\circ}$, que têm por escopo imprimir a necessária transparência aos atos da Administração Pública oportunizando aos administrados, mediante o acesso à informação clara, o controle e a fiscalização da atividade administrativa.

O princípio da publicidade se confunde com o próprio Estado Democrático de Direito. $\mathrm{O}$ art. $1^{\circ}$, parágrafo único, da vigente Constituição Federal dispõe que o poder emana do povo, que o exerce por meio de representantes. Ora, "pertencendo o poder ao povo, este não poderá ficar privado de informações concernentes ao agir da Administração Pública. Logo, aquele que atua e decide na qualidade de representante do povo, tem o dever acentuado de dar satisfação dos seus atos" (FERRAZ et alii, 2001. p. 84).

Ademais, é o princípio da publicidade que permite ao administrado ter o controle não apenas da legalidade dos atos praticados, mas também da moralidade subjacente às suas decisões.

Essa breve explanação sobre a confidencialidade e a publicidade, tem o escopo exclusivo de distinguir e situar os direitos protegidos pela Constituição, ambos materializados em forma de princípios: a necessária observância da publicidade na condução das atividades da Administração Pública e a inviolabilidade do direito à intimidade e à vida privada dos administrados.

Não se pode presumir que o administrado, ao voluntariamente se submeter às regras que regulamentam o procedimento conciliatório no âmbito da Administração Pública, abdique automaticamente da prerrogativa de manter a confidencialidade das informações e documentos que apresentar, ou mesmo abdique de eventuais direitos que vier a reconhecer na seara conciliatória. Como já se afirmou, o ambiente conciliatório deve ser amigável, confiável e seguro. De tal modo que, nas controvérsias entre particular e Administração Pública, deve-se assegurar ao particular a reserva necessária para que, seja pessoa física ou jurídica, não veja expostos dados negociais, sigilos industriais, informações financeiras e toda a sorte de informações que somente lhe dizem respeito e que, publicadas, possam Ihe acarretar sérios prejuízos.

Desse modo, parece razoável que nos procedimentos administrativos iniciados para intermediar controvérsia entre particular e Administração Pública, se observem os arts. $2^{\circ}$, 30 e 31 da Lei $n^{\circ} 13.140$, de 2015, bem como o artigo 5', inciso X, da Constituição Federal de 1988, protegendo o particular da curiosidade alheia e da exposição desnecessária de seus negócios.

Não se deve olvidar, no entanto, que, se de um lado da controvérsia existe um particular, merecedor da garantia da inviolabilidade de sua vida privada, do outro encontra-se a Administração Pública, cuja publicidade de seus atos é desejada e requerida pela sociedade.

Desse modo, não há que se falar em invalidade de um princípio por outro, mas de cedência recíproca, ou seja, a publicidade recuará o suficiente, e apenas o suficiente, para resguardar os interesses do particular, mas, uma vez realizado o acordo este será público, como são todos aqueles celebrados pela Administração Pública. 
Portanto, em síntese, o procedimento conciliatório entre particular e Administração Pública se submeterá às regras da sigilosidade, mas o seu produto final, qual seja, o acordo celebrado, se sujeitará ao princípio da publicidade, permitindo aos administrados o pleno e absoluto controle da atividade administrativa.

Tal prerrogativa - a sigilosidade -, no entanto, não alcançará o procedimento conciliatório desenvolvido apenas entre órgãos e entidades da Administração Pública. Não há que se invocar aqui qualquer sigilo. Embora, excepcionalmente, ele possa ocorrer, fato é que, como regra, tanto o procedimento conciliatório como o acordo final celebrado se sujeitarão ao princípio da publicidade.

Apesar de a questão sobre a confidencialidade ser novidade na doutrina e na jurisprudência e já dividir os doutrinadores entre aqueles que adotam a confidencialidade e aqueles que acreditam deva prevalecer a publicidade, amparados no argumento da superioridade do interesse público sobre o privado, bem como na necessidade de transparência que a Administração Pública deve conferir à sua atuação, a adoção de um entendimento moderado sobre o assunto parece ser a alternativa menos danosa tanto à implantação da nova política pública de solução consensual dos conflitos, estabelecida no art. $3, \S 2^{\circ}$, do NCPC, quanto à transparência dos atos praticados pela Administração Pública.

A prevalência da publicidade nos casos em que a controvérsia esteja restrita a órgãos e entidades da Administração Pública não significa a exposição leviana das informações e documentos apresentados pelos interessados a qualquer pessoa que não faça parte das negociações. A publicização plena do procedimento conciliatório (discussões, propostas de acordo, reconhecimento ou confissão de fato) teria o efeito deletério de afastar o Poder Público das mesas conciliatórias, ante o risco, infelizmente hoje onipresente, de espetacularização das notícias. Não é incomum que revistas ou jornais de circulação nacional peçam acesso a documentos e processos e, quando lhes é franqueado o acesso, editam e publicam seletivamente o que desejam, dando à publicação o viés adotado por seu editorial. De outro lado, a confidencialidade irá subtrair do administrado o poder de fiscalizar a Administração Pública.

Entre tais extremos, parece que o melhor caminho seja adotar o princípio da publicidade diferida ao procedimento conciliatório, garantindo aos órgãos e entidades da Administração Pública um ambiente sereno e confiável para a exposição honesta de suas dificuldades, mas franqueando, na sequência, ampla publicidade ao documento final produzido em seu bojo, qual seja, o acordo. Essa posição tem amparo, inclusive, na Lei de Acesso à Informação. Vejamos.

Ainda que ausentes outras motivações legais para eventual restrição às informações obtidas nas discussões e constantes no processo, não caberia de imediato dar-lhe qualquer publicidade, até mesmo por se tratar de documento preparatório que, nos termos do $\S 3^{\circ}$ do art. $7^{\circ}$ da Lei $n^{\circ} 12.527$, de 18 de novembro de 2011, combinado com os arts. $3^{\circ}$, XII, e 20 do Decreto $n^{\circ} 7.724$, de 16 de maio de 2012 , só teria seu acesso franqueado após o advento do ato ou da decisão que o adotasse como fundamento: no caso, após a eventual celebração de acordo para o término dos litígios, ou, na impossibilidade do acordo, do termo final que 
encerra o procedimento.

Ora, o procedimento conciliatório nada mais é que uma série concatenada de atos que têm como escopo a celebração do acordo. Por conseguinte, o acordo, firmado pelos interessados por meio de um termo de conciliação, é que é o ato final do procedimento. Quaisquer outros atos ou deliberações efetuadas no curso do procedimento têm natureza de atos preparatórios e, como tais, estão amparados pelo sigilo, nos termos do $\S 3^{\circ}$ do art. $7^{\circ}$ da Lei $\mathrm{n}^{\circ} 12.527$, de 18 de novembro de 2011 , combinado com os arts. $3^{\circ}$, XII, e 20 do Decreto $\mathrm{n}^{\circ} 7.724$, de 16 de maio de 2012.

Ademais, caberia neste momento pontuar também que o acesso irrestrito às tratativas, acarretaria a publicização de eventuais análises de riscos processuais aos quais estaria exposta a Administração Pública, o que poderia ser aproveitado contra seus interesses, fragilizando sua defesa em juízo, caso o procedimento conciliatório fosse infrutífero. A publicidade irrestrita imporia ao Estado litigar, na defesa do interesse coletivo, em condições desvantajosas, em flagrante afronta ao princípio da supremacia do interesse público. Afinal, a possibilidade de lançar mão de soluções de conciliação, recurso importante na busca do resultado que se verifique como o melhor possível, diante das circunstâncias de controvérsia judicial, pressupõe a avaliação dessas circunstâncias. A conciliação pode pressupor, inclusive, o reconhecimento pelos interessados da fragilidade de suas teses e the permite o controle dessas fragilidades. Ocorre, porém, que, não efetuado o acordo, a exposição dessas fragilidades comprometeria significativamente a paridade de armas que informa o princípio do contraditório e a isonomia processual, assim como o resguardo conferido pela ordem constitucional à ampla defesa e à supremacia do interesse público.

Por conseguinte, em prol da transparência dos atos públicos, bem como da necessidade de franquear ao administrado o controle da Administração Pública, o procedimento conciliatório entre órgãos e entes da Administração Pública deverá ser norteado pelo princípio da publicidade diferida, que resguardará, em última instância, a própria defesa do interesse público. A publicidade incide, portanto, sobre o ato pronto e acabado, mas não sobre o processo dialético.

A publicidade ilimitada poderia afastar o Poder Público da mesa de negociação, na medida em que a revelação de suas teses poderia lhe trazer futuramente eventuais prejuízos na seara judicial, acaso a conciliação fosse infrutífera.

Importante registrar que tanto a sigilosidade adotada nos procedimentos conciliatórios entre particular e Administração Pública como a publicidade diferida adotada nos procedimentos conciliatórios envolvendo apenas a Administração Pública não podem ser opostas aos órgãos fiscalizadores da Administração Pública, como Tribunal de Contas da União e Controladoria-Geral da União.

Por fim, há de se ressalvar a possibilidade de o acesso aos dados do procedimento conciliatório ser restringido pela incidência de sigilo legal de outra natureza, como a confidencialidade por razões de segurança da sociedade e do Estado (art. $5^{\circ}$, XXXIII, da Constituição Federal), ou pela classificação da informação, nos termos do disposto nos art. 23 e seguintes da Lei n 12.527, de 2011 (Lei de Acesso à Informação - LAI). 


\subsection{DIVERGÊNCIAS EM RELAÇÃO À APLICAÇÃO DA CONFIDENCIALIDADE}

Apesar da construção aqui proposta, é importante notar que, ainda que o princípio da confidencialidade tenha recebido destaque na nossa legislação, quando se trata de mediações na Administração Pública, parte da doutrina brasileira tem afastado sua incidência. Ancorados na ideia de que a mediação em direito administrativo deve observância plena ao princípio da publicidade, que tem sede constitucional (art. 37, caput, da Constituição de 1988), alguns autores brasileiros entendem que este deve preponderar frente ao princípio da confidencialidade da mediação ${ }^{3}$.

Além da previsão constitucional, para a doutrina nacional, a observância do princípio da publicidade nas mediações que tem como parte a Administração Pública se deve à incidência direta da Lei de Acesso à Informação (Lei 12.527/2011), a qual prescreve o sigilo como exceção nas questões concernentes à Administração Pública.

Segundo Ravi Peixoto (2015), deve prevalecer o interesse público da publicidade das informações, ainda que a exigência de publicidade, na mediação, desencoraje algumas partes à realização de acordos com o poder público. Assim, o autor entende que, caso a parte desista da mediação em razão de não concordar com sua publicidade, isso é justificável, já que entende ser o princípio da publicidade absoluto, preponderando sobre a mediação (PEIXOTO, 2015). Esse entendimento dá plena expressão ao direito administrativo tradicional, em que os dogmas não são superados, mesmo que isso signifique o sacrifício do diálogo buscado com o cidadão. O autor justifica com o argumento de que a mesma lógica, de preponderância do princípio da publicidade, teria sido seguida na autorização dos entes públicos na realização da arbitragem (PEIXOTO, 2015) ${ }^{4}$. Assim, segundo esse autor, por mais que a ausência da garantia de confidencialidade venha a afastar a realização de alguns procedimentos arbitrais ou de mediações no poder público, em nome do tratamento semelhante que deve ser dado a um e a outro instituto, a mediação na Administração Pública deve consagrar o interesse público na transparência e na publicidade dos procedimentos que envolvam entes públicos (PEIXOTO, 2015).

Por conta desses fatores, a mediação e a conciliação, das quais faça parte o Poder Público não seriam abrangidas pelo dever de confidencialidade, com a exceção dos casos em que a própria Lei 12.527/2011 preserva o sigilo das informações, o que é defendido por outros autores.

Luciane Moessa de Souza e Cristina Ayoub Riche (2016, p. 185) entendem que, dentre as peculiaridades que o regime de direito público traz à resolução consensual de conflitos, não se pode admitir a ideia de confidencialidade para as sessões conjuntas de medição, muito menos para a documentação produzida durante o procedimento de resolução consensual do conflito, a menos que se trate de informação acobertada por sigilo comercial, industrial, bancário, que coloque em jogo a intimidade ou a vida privada de particulares, ou, ainda, que se trate de algum segredo de Estado. Essa posição é adotada pelas as autoras em decorrência da aplicação, à mediação, da lógica trazida pela Lei de acesso à informação, a qual, segundo elas, ditaria um "novo paradigma para a Administração Pública, em que o 
acesso é a regra e o sigilo a exceção", na "consolidação do processo de transparência adotado no (SOUZA e RICHE, 2016, p. 183).

Ainda segundo as autoras, para que na mediação com os entes públicos pudesse incidir a confidencialidade, as informações deveriam ser classificadas, conforme possibilidade prevista na Lei 12. 527/2011 e regulamentada pelo decreto 7.724/2012. Assim, as informações eventualmente classificadas como reservadas seriam informações cuja divulgação poderia ser restrita por um determinado período (SOUZA e RICHE, 2016, p. 185).

Adotando posição semelhante, muitos autores brasileiros que tratam do tema consideram que, ainda no ambiente de mediação, impera a necessidade de se observar amplamente o princípio da publicidade que norteia a Administração Pública. Marco Antônio Rodrigues (2016, p. 386), afirma que, no caso da Administração Pública, a confidencialidade prevista no art. 166 deve ceder, via de regra, à publicidade, já que esta é princípio constitucional fundamental a incidir sobre a Administração. De outro lado, o autor pondera que, embora seja a regra geral a superação da confidencialidade pela publicidade, seria importante notar não ser esta última princípio absoluto, podendo existir valores que justifiquem sua não incidência em certas situações específicas, em virtude de previsão legal, ou mesmo por decisão judicial, em casos de autocomposição ocorrida no curso do processo (RODRIGUES, 2016, p. 386).

Luciane Moessa de Souza (2014, p. 87) explicita como incide a preponderância do princípio da publicidade em detrimento da confidencialidade, considerando ser inadmissível que, nos conflitos coletivos que envolvem entes públicos, seja como partes, seja como mediadores, pensar em confidencialidade como regra. Assim, a autora prega que a regra geral seria a da publicidade quanto a: a) termos do acordo; b) provas e estudos técnicos produzidos durante o procedimento de mediação; c) sessões deliberativas conjuntas, reunindo todas as partes no conflito, a fim de discutir propostas de soluções, informações levantadas ou firmar o acordo final (SOUZA, 2014, p. 86).

Esse foi o início do tratamento dado pela doutrina brasileira ao princípio da confidencialidade nas mediações que tem como parte a Administração Pública, onde a doutrina parece ter efetuado uma mera transposição do valor absoluto do princípio da publicidade do direito administrativo tradicional para o ambiente da mediação.

Assim, a prevalência do princípio da publicidade, adotado como regra, em detrimento do princípio da confidencialidade, admitido somente de forma excepcional, e de acordo com o teor da Lei de acesso à informação, foi a posição inicialmente dominante no Brasil, como ficou atestado não só pela doutrina que argumentou nesse sentido, mas que também refletiu na primeira ampla discussão sobre o tema, havida no I Fórum Nacional do Poder Público ${ }^{5}$, ocorrido em 2016, onde se aprovou o seguinte enunciado:

6. (art. 166, Lei 13.105/15; art. 2 ${ }^{\circ}$ Lei 13.140/15; Lei 12.527/11) A confidencialidade na mediação com a Administração Pública observará os limites da lei de acesso à informação (Grupo: Meios alternativos de solução de conflitos e a Fazenda Pública). 


\title{
5. DIREITO PÚBLICO CONSENSUAL
}

Elisa Eidt (2016, p. 167) já abordou a problemática da possibilidade da utilização da mediação pela Administração Pública, tendo concluído que a superação de certos dogmas concernentes ao direito administrativo tradicional pode trazer inúmeras vantagens ao Estado e ao cidadão por meio da utilização das vias autocompositivas para esse tipo de conflitos. Alfonso Masucci (2009, p. 15) também destaca a nova lógica, que aponta para uma mudança de paradigma no direito administrativo tradicional, pois reflete uma tendência que atravessa o direito administrativo, segundo a qual à lógica da decisão de um terceiro se contrapõe a lógica fundamental do diálogo. Essa tendência, segundo o autor, "auspicia un derecho administrativo dúctil, que supera la contraposición tradiccional entre Administração Pública e ciudadano, y se inspira en el diálogo".

Em mais um de seus escritos, nos quais faz recorrente proposta de uma nova visão do estado de direito, que teria uma dimensão voltada à co-construção da realidade, com participação do cidadão, Diogo de Figueiredo Moreira Neto destaca a superioridade das soluções negociadas,

\begin{abstract}
nas quais a consensualidade aplaina as dificuldades, maximiza os benefícios e minimiza assinconveniências para todas as partes, pois a aceitação de ideias e de propostas livremente discutidas é o melhor reforço que pode existir para um cumprimento espontâneo e frutuoso das decisões tomadas. O Estado que substituir paulatinamente a imperatividade pela consensualidade na condução da sociedade será, indubitavelmente, o que garantirá a plena eficiência de sua governança pública e, como consequência, da governança privada de todos os seus setores. (MOREIRA NETO, 2001, p. 142-143.)
\end{abstract}

Assim, frente ao desafio decorrente da pluralidade de valores consagrados pelo ordenamento constitucional, a partir de 1988, e que devem ser perseguidos e realizados pelo Estado (BATISTA JR., 2007, p. 58), a doutrina busca construir um direito administrativo que seja geral e igual no seu ponto de partida, mas que seja maleável e sensível às diferenças, a ponto de ser capaz de se adequar às diferentes nuances da realidade, conseguindo ao final, com justiça e eficiência, realizar os objetivos estatais, que, em última análise, tem por escopo promover o bem estar dos seus cidadãos.

Alguns autores emprestam ao fenômeno o termo transadministrativismo (MOREIRA NETO et alii, 2016, p. 15), o qual é inovador, na medida em que consagra o instituto da transação, que vai de encontro a vários dogmas do direito administrativo tradicional, confiando nas imensas possibilidades trazidas pelas diferentes formas de autocomposição, entre as quais consta a mediação, apostando nas arrojadas ferramentas acrescentadas ao arcabouço estatal tradicional, cuja potencialidade, entretanto, há de ser bem aproveitada.

Na mesma linha, Onofre Alves Batista Junior (2007, p. 107) defende uma Administração Pública que, sem rebelar-se contra a lei, não deixando portanto de ser garantística, seja também eficientística, isto é, torne-se capaz de atender da melhor forma possível as necessidades e os interesses da sociedade.

Assim, para a efetividade da utilização da mediação para o tratamento dos conflitos que envolvem a Administração Pública, há de se reconhecer as peculiaridades do direito administrativo, que pautam a mediação que é adequada e possível em matéria administrativa, 
mas também devem ser reconhecidas as nuances que os princípios inerentes à mediação acrescentam ao direito. Dessa forma, a influência do direito administrativo na mediação deve se dar de modo a respeitar o seu cerne, a fim de que este instituto não seja despojado do seu imenso potencial quando trazido à esfera do direito público.

Fernanda Tartuce (2015, p. 187) alerta neste sentido, afirmando que a observância dos princípios da mediação é crucial para que sua prática seja realizada de forma adequada em proveito das pessoas em crise. De acordo com a advertência da autora,

tanto jurisdicionados como advogados brasileiros padeceram de muitas mazelas ao longo dos anos por conta de práticas que, apesar de denominadas conciliatórias, não respeitavam princípios nem técnicas de conciliação, mas buscavam a todo custo a extinção dos processos judiciais (TARTUCE, 2015, p. 187).

Assim é que, tanto na França como na Alemanha e Inglaterra, ainda que interna à Administração, a fim de que o procedimento seja fiel ao que se propõe, a prática da mediação respeita as características do direito administrativo, sem de outro lado deixar de preservar suas características intrínsecas.

\begin{abstract}
Más en concreto, el respeto de un nivel mínimo de garantías permite a cada una de las partes, (...)un conocimiento cuidadoso y adecuado de los términos del litigio. Permite superar la asimetría informativa que a menudo subsiste entre las partes, y valorar en términos objetivos la posición propia y ajena. Permite a las partes dialogar constructivamente por una solución justa y transparente del litigio. Permite una negociación en términos paritarios, pues ninguna negociación paritaria eficaz puede poner en marcha sin la disposición de las informaciones necesarias. En síntesis, el respeto de este nivel mínimo de garantías permite reconocer en el procedimiento de mediación un medio alternativo a la solución de los litigios creíble. Sin el respeto a esta condición, se caería en la retórica de las virtudes salvíficas de los medios alternativos de resolución de los litigios. (MASUCCI, 2009, p. 35, grifado)
\end{abstract}

$\mathrm{Na}$ busca da efetiva solução consensual, possível apenas em um ambiente de confiança, é necessário ponderar os princípios que aparentemente colidem, o que só é possível com a superação da tradicional visão dogmática do direito administrativo.

Nesse sentido, vemos que o consenso na Administração Pública insere-se no referencial teórico inaugurado por um novo direito administrativo, o direito público consensual, vigente a partir da Constituição de 1988, balizado nos princípios de direito administrativo, interpretados à luz do conjunto dos valores constitucionais do Estado Democrático e Social, instituído pela carta constitucional. A interpretação à luz dos valores constitucionais do Estado Democrático e Social implica na flexibilização dos princípios da Administração Pública à vista de outros princípios, o que possibilita sua interpretação em harmonia com os princípios da mediação, agora também normatizados.

\title{
6. CONCLUSÃO
}

O procedimento conciliatório entre particular e Administração Pública será orientado pelo princípio da sigilosidade, albergado nos arts. $2^{\circ}$, inc. VII; 30 e 31 da Lei $n^{\circ} 13.140$, de 26 de junho de 2015, mas o termo de acordo, ou o termo de encerramento, no caso de as tratativas serem inexitosas, se sujeitará ao princípio da publicidade.

O procedimento conciliatório entre órgãos e entidades da Administração Pública será norteado pelo princípio da publicidade diferida, o que implica em dizer que tanto o acordo ou 
termo de encerramento, bem como as informações e documentos que o motivaram também serão públicos, mas terão a sua publicidade postergada para o final das tratativas.

A garantia do sigilo em relação às informações obtidas no procedimento de mediação, durante e após sua realização, limitando-se a publicidade somente ao resultado obtido, coaduna-se com o instituto da mediação, e também com as disposições legais a respeito, arts. 30 e $31^{6}$ da Lei de Mediação. Essa solução compatibiliza o princípio da confidencialidade da mediação com o princípio da publicidade do direito administrativo.

Dentro do arcabouço teórico do direito público consensual, a mediação em direito administrativo deve ser reconhecida como instituto regido harmoniosamente pelos princípios da confidencialidade (em relação ao procedimento) e da publicidade (em relação ao resultado), sem que a prevalência absoluta de qualquer deles comprometa o procedimento ou o ato administrativo resultante, de modo a preservar as imensas potencialidades do instituto, de um lado, bem como a devida transparência do ato administrativo, o que vem em benefício da Administração Pública e do cidadão.

\section{NOTAS}

1. Art. $7^{\circ}$. Confidencialidade da mediação. 1. Dado que se pretende que a mediação decorra de uma forma que respeite a confidencialidade, os Estados-Membros devem assegurar que, salvo se as partes decidirem em contrário, nem os mediadores, nem as pessoas envolvidas na administração do processo de mediação sejam obrigadas fornecer provas em processos judiciais ou arbitragens civis ou comerciais, no que se refere a informações decorrentes ou relacionadas com um processo de mediação, exceto: a) caso tal seja necessário por razões imperiosas de ordem pública do Estado-Membro em causa, em especial para assegurar a proteção do superior interesse das crianças ou para evitar que seja lesada a integridade física ou psíquica de uma pessoa, ou; b) caso a divulgação do conteúdo do acordo obtido por via de mediação seja necessária para efeitos da aplicação ou execução desse acordo. 2. Nada no n. 1 obsta a que os Estados-Membros apliquem medidas mais rigorosas para proteger a confidencialidade da mediação.

2. O termo Alternative Dispute Resolution - ADR - foi amplamente utilizado por nos EUA a partir da disseminação dessa nova cultura. Atualmente, ainda que a doutrina prefira o termo resolução adequada de conflitos, o termo tradicional é encontrado em muitos trabalhos de autores norte-americanos, por isso aqui a referência.

3. Ravi Peixoto refere ainda a menção à publicidade no Poder Judiciário (art. 93 , IX, da CF), reforçado e densificado pelo art. $8^{\circ}$, do CPC/2015. (PEIXOTO, 2015).

4. É provável imaginar que, por diversas vezes, a arbitragem tenha um caráter confidencial, justamente para evitar os problemas inerentes à existência de um litígio, tais como a desconfiança do mercado em relação a uma empresa, a divulgação de informações desfavoráveis aos participantes etc. No entanto, o art. $1^{\circ}$., $\S 3^{\circ}$., da Lei 9.307/1996, com a redação dada pela Lei 13.129/2015 afirma expressamente que "A arbitragem que envolva a administração pública será sempre de direito e respeitará o princípio da publicidade". (PEIXOTO, 2015)

5. Segundo apresentam os organizadores: "Nos dias 17 e 18 de junho de 2016, na cidade de Brasília, ocorreu o I Fórum Nacional do Poder Público, sob a coordenação de Marco Antônio Rodrigues (Procurador do Estado do Rio de Janeiro), Rita Dias Nolasco (Procuradora da Fazenda Nacional) e Paulo Mendes (Procurador da Fazenda Nacional). O evento reuniu 66 estudiosos do Direito Público (em especial, processualistas civis, administrativistas e tributaristas) de todo o Brasil, dentre advogados públicos, advogados privados e magistrados (relação anexa), e teve por objetivo interpretar o novo Código de Processo 
HECK, Tatiana de M. L.; BOMBINO, Luciana M. - Princípio da confidencialidade e princípio da publicidade: incidência e limites sobre as tratativas conciliatórias na Administração Pública

Civil - Lei n. 13.105/15, com as alterações promovidas pela Lei n. 13.256/16 - e seus impactos nas relações em que a Fazenda Pública seja parte, com a elaboração de enunciados. O objetivo principal foi que todos participassem efetivamente das discussões e reflexões despidos de preocupações ideológicas ou de vaidades acadêmicas, de modo a todos juntos contribuirmos para a formação da ciência processual, diante de um novo Código de Processo Civil"

6. Art. 30. Toda e qualquer informação relativa ao procedimento de mediação será confidencial em relação a terceiros, não podendo ser revelada sequer em processo arbitral ou judicial salvo se as partes expressamente decidirem de forma diversa ou quando sua divulgação for exigida por lei ou necessária para cumprimento de acordo obtido pela mediação.

$\S 1^{\circ} \mathrm{O}$ dever de confidencialidade aplica-se ao mediador, às partes, a seus prepostos, advogados, assessores técnicos e a outras pessoas de sua confiança que tenham, direta ou indiretamente, participado do procedimento de mediação, alcançando:

I - declaração, opinião, sugestão, promessa ou proposta formulada por uma parte à outra na busca de entendimento para o conflito;

II - reconhecimento de fato por qualquer das partes no curso do procedimento de mediação;

III - manifestação de aceitação de proposta de acordo apresentada pelo mediador;

IV - documento preparado unicamente para os fins do procedimento de mediação.

$\S 2^{\circ} \mathrm{A}$ prova apresentada em desacordo com o disposto neste artigo não será admitida em processo arbitral ou judicial.

$\S 3^{\circ}$ Não está abrigada pela regra de confidencialidade a informação relativa à ocorrência de crime de ação pública.

$\S 4^{\circ}$ A regra da confidencialidade não afasta o dever de as pessoas discriminadas no caput prestarem informações à administração tributária após o termo final da mediação, aplicando-se aos seus servidores a obrigação de manterem sigilo das informações compartilhadas nos termos do art. 198 da Lei no 5.172, de 25 de outubro de 1966 - Código Tributário Nacional.

Art. 31. Será confidencial a informação prestada por uma parte em sessão privada, não podendo o mediador revelá-la às demais, exceto se expressamente autorizado.

\section{REFERÊNCIAS}

ALMEIDA, Diogo A. Rezende; PANTOJA, Fernanda. Natureza da mediação de conflitos. In: ALMEIDA, T.; PELAJO, S.; JONATHAN, E. (Coord.). Mediação de conflitos para iniciantes, praticantes e docentes. Salvador: Juspdium, 2016. p. 87-99.

BATISTA JR. Onofre Alves. Transações administrativas. Belo Horizonte, Quartier Latin, 2007.

BRAGA NETO, Adolfo. Capacitação em mediação de conflitos - estudo e vivência gradual dos novos paradigmas na construção do ser mediador. In: ALMEIDA, T.; PELAJO, S.; JONATHAN, E. (Coord.). Mediação de conflitos para iniciantes, praticantes e docentes. Salvador: Juspdium, 2016. p. 771-802.

EIDT, Elisa Berton. Autocomposição na Administração Pública. Santa Cruz do Sul, Essere nel Mondo, 2017. Disponível em: http://www.esserenelmondo.com/it/diritto-autocomposiCAo-na-administraCAopUblica-ebook100.php.

FERRAZ, Sérgio, Dallari, Adilson Abreu. Processo Administrativo. São Paulo, Malheiros, 2001. 
HECK, Tatiana de M. L.; BOMBINO, Luciana M. - Princípio da confidencialidade e princípio da publicidade: incidência e limites sobre as tratativas conciliatórias na Administração Pública

GOLDBERG, Stephen B.; SANDER, Frank. E. A.; ROGERS, Nancy H.; COLE, Sarah R. Dispute resolution. Negotiation, mediation and other processes. 4 ed. New York, Aspens, 2006.

HOUAISS, Antônio. Dicionário Houaiss da Língua Portuguesa. Rio de Janeiro, Objetiva, 2001.

JONATHAN, Eva; ALMEIDA, Rafael Alves de. Dinâmica da mediação: etapas. In: ALMEIDA, T.; PELAJO, S.; JONATHAN, E. (Coord.). Mediação de conflitos para iniciantes, praticantes e docentes. Salvador: Juspdium, 2016. p. 241-256.

MASUCCI, Alfonso. El procedimiento de mediación como medio alternativo de resolución de litigios en el derecho administrativo. Esbozo de las experiencias francesa, alemana e inglesa. In: Revista de Administración Pública. Madrid, Centro de Estudios Políticos y Constitucionales, enero-abril 2009, p. 9-35. Disponível em: https://dialnet.unirioja.es/descarga/articulo/2979639.pdf.

MIRANDA, Francisco Cavalcanti Pontes de. Tratado de direito privado. Rio de Janeiro, Borsoi, 1995.

MOREIRA NETO, Diogo de Figueiredo. Poder, Direito e Estado: o Direito Administrativo em tempos de globalização. Belo Horizonte: Fórum, 2011.

MOREIRA NETO, Diogo de Figueiredo; ALMEIDA, Aline Paola C. B de; GARCIA, Flávio Amaral. O futuro da Advocacia-Pública: A ação preventiva e proativa. In: Revista Jurídica da Procuradoria-Geral do Estado do Paraná, Curitiba, n. 7, 2016, p. 11-36.

NETTO, Fernando Gama de Miranda; SOARES, Irineu Carvalho de Oliveira. Princípios procedimentais da mediação no novo Código de Processo Civil. In: A mediação no novo Código de Processo Civil. 2. ed. Rio de Janeiro: Forense, 2016, p. 109-119.

NUNES, Antonio Carlos Ozório. Manual de mediação: Guia prático da autocomposição. São Paulo, Editora Revista dos Tribunais, 2016.

PEIXOTO, Ravi. Sobre o Princípio da Confidencialidade na Mediação e na Conciliação. Em: http:// www.adambrasil.com/sobre-o-principio-da-confidencialidade-na-mediacao-e-na-conciliacaol. Acesso em: 17 fev. 2018

RODRIGUES, Marco Antônio. A Fazenda Pública no Processo Civil. 2. ed. Sao Paulo, Atlas, 2016.

SOUZA, Luciane Moessa de. Resolução consensual de conflitos coletivos envolvendo políticas públicas. 1. ed. Brasília, Fundação Universidade de Brasília, 2014.

SOUZA, Luciane Moessa de; RICHE, Cristina Ayoub. Das câmaras de mediação. In: A mediação no novo Código de Processo Civil. 2. ed. Rio de Janeiro: Forense, 2016, p. 179-221.

TARTUCE, Fernanda. Mediação nos conflitos civis. 4. ed. São Paulo, Método, 2015.

VASCONCELOS, Carlos Eduardo de. Mediação de conflitos e práticas restaurativas. 4. ed. São Paulo: Método, 2015.

Recebido em: 19/10/2018

Aceito em: 04/12/2018 